\title{
11
}

\section{Aeromobilities and Academic Work}

\author{
Claus Lassen
}

\section{Introduction}

Recent decades have seen an increase in academic air travel as part of a larger transformation and globalisation of modern work life away from industrial and hierarchical work towards much more flexible, networked and mobile work, of which air travel often is a critical component (Castells, 2001; Sennett, 1998; Vesala \& Tuomivaara, 2020). This is reflected in growing aeromobilities, with more than 4.5 billion scheduled flight passengers globally in 2019 (Statista, 2020). Many academics today live a mobile life on the move (Elliott \& Urry, 2010) as members of the smooth 'airworld' (Kirn, 2001: 8-9), and the new airborne elite of cosmopolitan tourists (Bauman, 1998). In a world where only 11 per cent of the population took a flight in 2018, and only 4 per cent flew abroad, academics are part of the frequent flying 'super emitters' (Gössling \&

C. Lassen $(\bowtie)$

Centre for Mobilities and Urban Studies (C-MUS), Aalborg University, Aalborg, Denmark

e-mail: clla@create.aau.dk 
Humpe, 2020). This group, representing just 1 per cent of the world's population, has caused half of aviation's carbon emissions (ibid.). Such intensive airborne academic work practices seem particularly problematic due to the significant larger climate impacts and higher energy consumption related to flying over a long distance in the stratosphere compared to movement at ground level (Høyer \& Næss, 2001; Lassen, 2005).

Despite the above-listed implications of air travel, there exist a number of drivers for academics' increased travel activity. Academics travel globally to exchange knowledge, to do research, to teach and present research, also creating and maintaining networks that are important career strategies for many academics (Lassen, 2009b). Much of such academic work seems to accommodate a need for face-to-face interaction, co-presence and proximity (Urry, 2002, 2003, 2007). Lately, COVID-19 has temporarily put aviation on standby and increased attention towards the idea that more meetings may be held on the screen. The current standby of aviation has generally created an opportunity for reflection on the existing work practices and a change to explore the opportunities to work and travel differently in the future. The aim of this chapter is to contribute to these reflections by raising a number of questions in relation to this: Why do academics travel and meet face-to-face? Why has academic air travel increased during the last decades? What are the main drivers behind such development? Is it possible to imagine a future for academics with less face-to-face meetings? How can this potential be achieved?

In the following section, based on the new mobilities turn (Urry, 2007; Jensen, 2013; Adey, 2010; Kaufmann, 2002) including aeromobilities studies (Cwerner et al., 2009; Lassen, 2006, 2009a), this chapter first examines the transformation of work and the importance of aeromobilities for late modern work, which sets the context for contemporary academic work practices. Next, this chapter examines academic work in particular and shows that physical meetings and face-to-face interactions play a central role in academic work and aeromobilities. The chapter argues that, for aeromobilised academic work practices to be carried out in the future with a lower climate footprint, a stronger differentiation between the forms of meetings and co-presence obligations is necessary. Finally, the chapter presents a tool that provides a more detailed understanding of which types of meetings that in particular require co-presence 
and face-to-face communication, and which types of meetings that could just as well—or perhaps even better and more efficiently-be carried out as virtual meetings. However, as stressed at the end of the chapter, such an approach seems to require a much greater focus on, and understanding of, the aeromobility management at academic institutions in the future.

\section{Global Work and Aeromobilities}

In this first section, I will argue that it is difficult to understand and explore academic work and travel independently of the wider transformation of work, and in relation to this, the (aero)mobilisation of work. The rise of a more global networked and knowledge-based economy has fundamentally changed the context of academic work in recent decades by creating a framework for a new labour market based on globalisation, knowledge, mobilities, flexibility, individualisation and networking. A transformation which fundamentally also have influenced and changed the role of academic work at a societal level. Therefore, in order to understand why academics travel in relation to their work, a first important step is to explore the general changes and shifts of the new labour market, with a particular focus on the role of aeromobilities. In the following sections, I will therefore begin this chapter by exploring more generally five interdependent components of such work transformation where especially aeromobilities both make such new labour market possible and are drivers for its development and logic.

First, work-related aeromobilities are closely related to a move away from Fordism - an economic system based on mass production, standardised work routines, mass labour, centralised, industrialised and wagebased societies. The new post-Fordist network-based economy is one built on innovation, globalisation and decentralisation of work, workers and companies and is based on flexibility and adaptability (Castells, 1996). Such an economy is characterised by the individualisation of work organisation, the diverse localisation of activities and the ability to network these around the individual worker. This creates a new urban space for endless mobility built on information and communication flows 
(Castells, 2001: 234). Although, according to Castells, the majority of the workforce still has a workplace that they regularly frequent, a growing proportion of employees also work from home, the car, the train, the plane, the port or the hotel and on holiday or at night. Work has also become increasingly mobile, particularly in knowledge-intensive types of work (Vesala \& Tuomivaara, 2020: 223). Nowadays, highly educated employees take more and more time in the field with clients and partners. They travel around the world across metropolitan areas and countries all while communicating with their workplace via the Internet, smartphones and social media (ibid.).

As a result of these changes, companies are increasingly reducing office space for employees, such that they only have the space they use when they actually use it (ibid.). According to Vesala and Tuomivaara, 'mobile work' must therefore not only be understood as involving the physical movement of workers between various work locations but as a mental state that results from a situation in which the spatial arrangement of work has become fluid, contingent and open to change (Vesala \& Tuomivaara, 2020: 225). In that respect, mobile work is not only associated with information communications technology but also with various processes related to the changing organisation of work (ibid.). Jones, therefore, calls for a reconceptualisation of work through the notion of 'global work'. Rather than understanding work as a practice undertaken by social actors located in discrete material spaces and framed in a linear chronology, Jones argues for global work 'as a complex set of spatialized practices involving humans and non-humans ... and which is constituted in relational space with a disjunctive, non-linear chronology' (Jones, 2008: 15). Jones stresses that there is no local 'opposite' of such global work because all forms of contemporary work are potentially constituted through relations that exist globally (ibid.).

Second, in the global-, flexible- and knowledge-driven economy, networks and networking have become a fundamental component of work. According to Wittel (2001), the term 'network sociality' should be understood as opposed to the community because, for network sociality, social relations are not narrative but informative. These relations are not based on mutual experience or common history, but primarily on the exchange of data and on constantly 'catching up'. Wittel argues that a shift from an 
experiential sociality to an informative sociality is especially generated by mobility and speed (ibid.: 68). Thus, in network sociality, the social kit consists not of bureaucracy, but of information created based on a projectto-project foundation. This foundation is established through the movements of ideas, the establishment of modern standards and protocols, the emergence of protected information and on the basis of communication and transport systems (ibid.):

Network sociality is a technological sociality insofar as it is deeply embedded in communication technology, transport technology and technologies to manage relationships. It is a sociality that is based on the use of cars, trains, buses and the underground, of aeroplanes, taxis and hotels, and it is based on phones, faxes, answering machines, voicemail, videoconferencing, mobiles, email, chat rooms, discussion forums, mailing lists and web sites. Transportation and communication technologies provide the infrastructure for people and societies on the move. (Wittel, 2001: 69-70)

Third, global work takes place materially in what I previously termed 'corridors' (Lassen, 2006) stretched by airplanes, airports, air spaces, motorways, trains and metros, hotels, offices, meetings rooms and conference and convention centres. Global work evolves in high-speed spaces, in which highly mobile global workers move on the way to the next meeting, next hotel, next bar and next country (see Lassen, 2005, 2009a). The airplane is a fundamental component of such corridor systems (Urry, 2007). For many global workers, flying is not a novelty but simply a means of transportation to go to the requested destination. It is a 'global bus', lacking the attraction and mystery that air travel abroad historically held for people and societies (Lassen \& Jensen, 2004). The time of the corridors is 'clock time' (Lassen, 2005: 162), which means that travellers aim to move as efficiently and quickly as possible between planes, taxis, hotels and workplaces. Such high-speed movement by air leaves little room for experiencing and sensing the places and cultures through which travellers move on the way to their destination. Employees travelling in these corridors materially contribute to their construction through spatial practice. Their cognitive experience and logic are also framed by the corridors. This represents a spatial form of organisation, 
where the corridors function as a mechanism of selection, that picks and chooses such that the travellers are distributed in accordance with the logic of the space of flows (Castells, 1996). In this way corridors materialise the paradox of high-speed travel identified by Elliott and Urry (2010), between individual creation and system dependency; the social structure of human agency and individual life is substantially and increasingly constituted through mobility systems (Elliott \& Urry, 2010: 13; see also Urry, 2007). This means that although the novel textures of individual life and travel attract significant research interest, such practices are also highly predictable, routinised and uniformed (Fig. 11.1).

Fourth, in the network-driven workplace, the boundaries between work and private, work and play, colleagues and friends, workplaces and places of experience seem to increasingly blur. Wittel describes how the times of play and the time of work are less tightly drawn, as going to

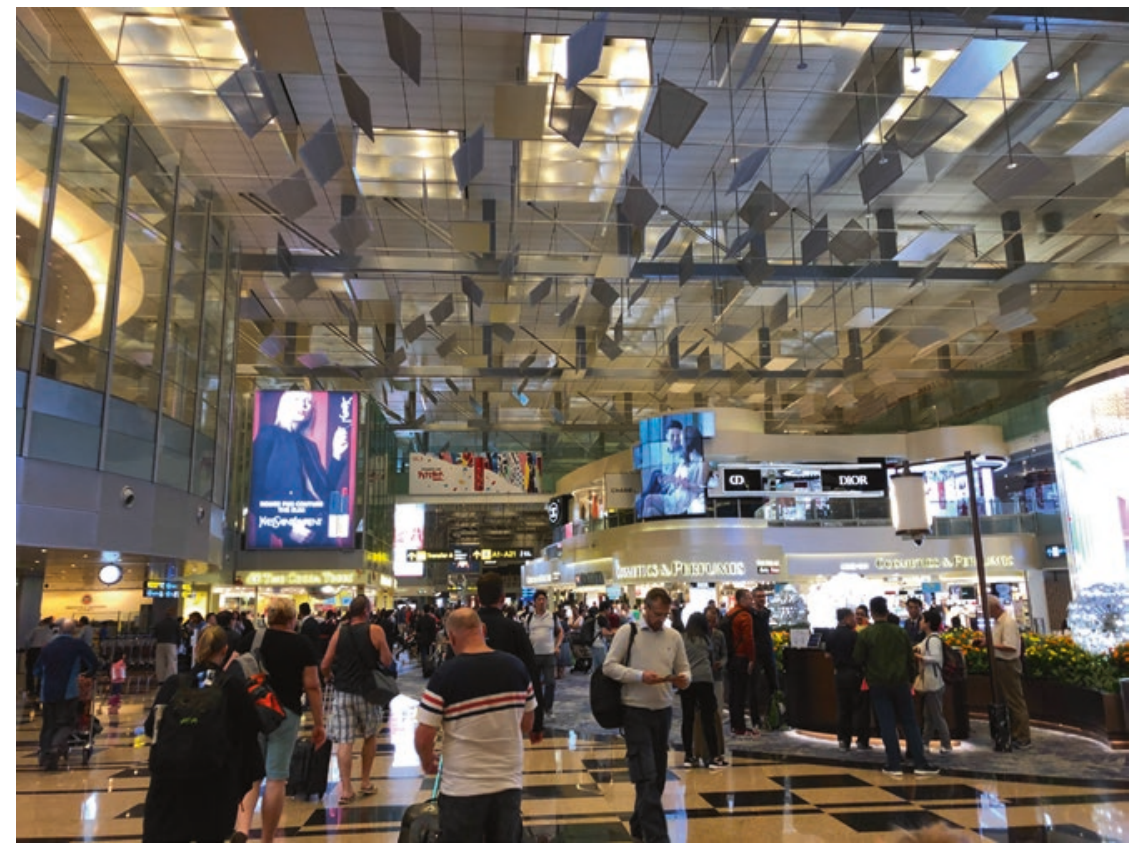

Fig. 11.1 The corridor experiences. Singapore Changi Airport. Picture: Claus Lassen 
parties and other networking activities are transformed to become part of work (Wittel, 2001: 68-9). Here there are overlaps between work and friendships. This overlap can also be seen where 'the project' and the work team are key organising features of work and leisure networks (Urry, 2007: 222). As Vesala and Tuomivaara stress in relation to telework, work carried on outside the main workplace potentially includes a wide range of work practices, many of which challenge the boundary between work and leisure. This overlap typically involves new leisure-like and aestheticised organisational spaces that invite workers mentally to travel away from toil and routine (ibid.: 225-226). Workplaces 'are increasingly designed to look like play places and leisure places, through a kind of designed "Starbuckization" (Urry, 2007: 221). Similarly, in relation to aeromobility, the boundaries between business and tourism are slowly becoming less important. In his work on business travel and leisure tourism, Kellerman points out:

Clear-cut differentiations between business and leisure tourism have blurred for all the three major dimensions of tourism: people, places and activities. For people, business meetings by business people may yield leisure visits by these business persons and vice versa, leisure visits may bring about business ideas and opportunities yielding future business visits by vacationers. As for places and activities, leisure tourism and business visitors may share the same transportation, lodging and entertainment facilities. (Kellerman, 2010: 173)

Earlier, I illustrated how this tendency for boundaries to blur is particularly visible in academic international air travel. My examination of academic international air travel at Aalborg University showed that one in four trips made to a conference inside Europe (excluding Scandinavia) was to the Mediterranean coast and not only to large cities but also to smaller towns that are rather popular tourist destinations (Lassen, 2006; see also Høyer \& Næss, 2001 on conference tourism).

Fifth, as Elliott and Urry stress, the exploration of fast mobilities is fundamentally significant to the transformation of personal identity and life strategies (Elliott \& Urry, 2010: 3). As Beck (2002) points out, a new cosmopolitanism seems to stem from the transformation processes that 
diminish the importance of the national border, support time-space compression and increase the international network relations between national communities. This is especially exemplified through economic globalisation. However, there are also other elements that contribute to this, namely that people increasingly act internationally, work internationally, love internationally, marry internationally, research internationally, grow up and are educated internationally and finally live and think internationally (Beck, 2002: 80). Work-related aeromobility thus delivers important material and symbolic support to new cosmopolitan identities of global workers (Lassen, 2005). It is characteristic of such identities that they need to be enacted, performed and represented to others (Elliott \& Urry, 2010: 79). According to Elliott and Urry, the globalisation of mobility extends into the core of the self:

Mobility-especially the demands that issues of movement place upon people-has become a feature of most societies. One can note pre-industrial mobility systems as horse riding, coach travel, shipping and especially walking. In conditions of advanced globalization, by contrast, soft-driven, digitized systems of mobility-from air traffic control systems to mobile telephony-exert new demands upon the self and its capacities for psychic reorganization. (Elliott \& Urry, 2010: 3)

Such demands or burdens, as well as the new possibilities related to mobile life, and globalisation of mobility mean that workers in the new economy constantly need to build and draw on different coping strategies (Lassen \& Jensen, 2004). Humans need to juggle their work, mobility demands, leisure, family and various forms of 'identity accessories' such as places and intensive movement between these places. This means that for some mobile workers, the contribution to the global work identity is an important driver for being on the move. But global mobilities are not a homogeneous phenomenon (Bauman, 1993: 240). Those with fewer choices and lower self-determination rather experience their mobile life as a burden and may face ambivalence and stress in their attempt to get all the different elements of everyday life to come together in a way that makes sense to them (see Lassen, 2009a for a further elaboration of the social consequences of work-related aeromobility). 


\section{The Change in Academic Work}

Next, I examine academic work, where physical meetings and face-toface interactions play a central role in academic work and aeromobilities. I begin by briefly looking at academic work and its changing nature. The traditional understanding of academia focuses on the activities and work done at universities and colleges with a strong element of academic autonomy, that is, 'the right of staff in higher education to determine the nature of their work' (Henkel, 2005: 170). Moreover, it is important not to forget that academic work not only covers scientific work but also involves a great deal of teaching and administrative work (Lassen, 2005: 120). However, the movement described earlier towards a more networked, flexible and globalised knowledge-based economy has had a significant impact on all areas of academic work during the past decades. Storme et al. identify a number of trends on various scales that have reshaped the nature of academia:

- transnational collaboration and competition are increasingly valued and strengthened by the neoliberal internationalisation-cumbenchmarking' discourse in higher education;

- universities are centre stage in globalised, knowledge-intensive service economies and are increasingly seen as potential engines of regional economic growth because of their capacity to generate both highly skilled people and innovative research;

- adoption of behaviour understood as entrepreneurial, strategic and market-led on the part of institutions, departments and individual academics as universities take on the logic of private companies, providing resources in return for production and performance objectives;

- changing labour conditions mean it is more and more common to employ early career researchers on a fixed-term project basis with reduced job security. Moreover, there is a move towards boundary-less careers with little or no organisational or institutional loyalty; and

- an increasing abundance of codified knowledge on the Internet. This comprises not only knowledge in the form of peer-reviewed publications in indexed electronic journals, but increasingly, more unfinished, 
often overlapping and sometimes contradictory or outright unreliable material. This abundance of information creates challenges for academics, not least in terms of sense-making and keeping abreast of knowledge within a particular subfield. (Storme et al., 2017: 409-410)

Henkel argues that higher education and science increasingly have become important instruments of national economic policy and concludes that: 'higher education institutions and their members were subject to unprecedented government steerage and scrutiny but also had to locate themselves and compete in various forms of markets' (Henkel, 2005: 160). Therefore, as Henkel also emphasises, the interaction between disciplines, institutions and individuals is now much more complex; academics are expected to engage across the boundaries of the institution as much as within them (ibid.: 164). As Fumasoli et al. show in a study on European academics, this movement towards increased competition and external work is closely connected with international mobility:

This competition between institutions values international mobility as a signal of excellence ... international mobility is not being generalised as a necessary step of academic careers but is becoming a distinctive feature that facilitates early careers and recruitment. International mobility is perceived by the interviewees as an opportunity to network and accumulate social capital as well as to increase independence and self-assertion. (Fumasoli et al., 2017: 206)

The described changes in academic work mean that it is not only participation in international conferences, congresses, seminars and workshops that are key components of a successful academic career. Other such components include joint international publications, research visits and stays; joint-research projects across professions, institutions and countries; guest lectures and courses; guest stays in laboratories for learning new techniques and methods; student exchanges; and relationships with external companies and foundations nationally as well as internationally. 


\section{Why Do Academics Travel?}

To cope with the above-described external demands for mobility, as well as the individual academic workers' motility (Kaufmann \& Audikana, 2020), networks and networking are important elements for both research and teaching. At universities, knowledge is exchanged, and knowledge production takes place, via networks. As a female professor explains: 'I'm dependent on the fact that I have some networks, my career and my job and my success depend on the fact that I have the networks, because otherwise I would not be able to participate in events, projects, etc. So, I have to have them professionally to be able to do my job, you could say' (Lassen, 2005: 117). Networks can have many different functions, so the motivation to create a relationship may be a need for specialised knowledge that can only be found in a few places around the globe or could be a desire to enter into an academic-knowledge exchange with other researchers. For example, it can be important, if a researcher works alone, to make contacts with other researchers who also work alone or perhaps are members of a larger research community at an institution to which doors can be opened via a connection. The invitation to take part in a formalised network means that the researcher has the opportunity to publish with other researchers. A female professor gives an example of this:

It is at least important for researchers to know about the situation is in your field and such and it can be difficult to find out if you are not part of some network. Furthermore, I would say that a lot of the money for research nowadays also comes from projects, and projects are always based on network knowledge. When you establish a project, you do it based on who you know from your network, because then you can quickly get the project described, so being part of a network, it is both in terms of knowledge and resources. (Lassen, 2005: 136-137)

When it comes to everyday work problems, networks open doors and strengthen an individual's career. The ability of academics to make acquaintances relevant to their work is a critical component in networking. Knowing others or being known by others are important 
instruments for being successful in the workplace and advancing career opportunities. However, it is not just about building relationships but also about what positions are held by the people with whom you create relationships and, most importantly, what relationships they have with other significant people (Wellman \& Haythornthwaite, 2002; Urry, 2007). For example, a researcher may be dependent on being known among others and being part of the right circles to strengthen their opportunities to publish and participate in different projects. In this regard, a female associate professor compares network-based academic working life to the working conditions for an actor:

It depends, of course, on whether there are influential people in these networks or not, but I certainly think that it is important for one's career if one should need it, to be able to refer to well-known academics in one's professional field. It's like being an actor, there are some who are more famous than others, some who are more important than others and that's just the way it is. (Lassen, 2005: 140)

In some cases, acquaintances lead to friendships over time (Feld \& Charter, 1998: 140). When a relationship extends beyond the work sphere, it takes on the character of a personal friendship, where the individuals are trying to help each other with problems, not only related to work but also in other areas of everyday life. Such work-related networks of acquaintance and friendship are, among other things, maintained by various forms of virtual communication, which make it possible to work, socialise and stay connected at a distance, even when on the move (Urry, 2007: 174).

\section{The Need for Co-presence and Face-to-Face Talks}

As Urry notes, however, 'central to networks then are very "costly" meetings, communication and travel' (Urry, 2007: 231). Boden and Molotch (1994) argue that modern systems and relationships not only are produced through virtual communication but just as much through what 
they call 'co-presence'. Co-presence remains the fundamental way of human interaction and socialisation-the 'primordial site for sociality' (Boden \& Molotch, 1994: 258). When people are unable to achieve the needed co-presence, they usually try to compensate in the best way they can. For example, a Skype or Microsoft Teams meeting will be better than a phone call and an e-mail better than a letter. Boden and Molotch argue that humans prefer co-presence to other forms of communication, and this form of interaction changes in abundance during late modernity (Boden \& Molotch, 1994: 277). Co-presence interactions dominate other forms of communication because they are 'thick' with information (ibid.: 259). By this, the authors mean that under any media condition, words derive their meanings mainly from contexts, and here co-presence delivers far more context than any other form of human exchange. Context includes other words, facial gestures, body language and voice intonation (ibid.: 259). Often the most important communication between different actors is carried out via co-presence, which Boden and Molotch predict also will be the case in the future. Even though this may change over time, the basic need for co-presence therefore sets limits on the degree and nature of the organisational, temporal and spatial transformation that new technologies can introduce (ibid.).

Urry (2002) stands on the shoulders of Boden and Molotch's analysis and argues that periodic co-presence is a fundamental ingredient in social relationships. Urry further opens the concept in relation to physical travel and movement by identifying three modes of co-presence in which physical proximity is obligatory, appropriate or desirable: face-to-face, facethe-place and face-the-moment (Urry, 2002: 262; Urry, 2003: 163). Face-to-face co-presence offers the opportunity for participants to build trust through, among other things, eye contact and body language, and to be able to read the other person's response to what is said and done. Such information is important in dealing with network relationships, projects and work assignments across national borders. Face-to-face interaction also provides an opportunity to talk more deeply and communicate more intensely. Face-to-face communication makes it possible to communicate in a more in-depth way on complex topics similar to other forms of communication. In face-to-face conversations 'topics can come and go, misunderstandings can be quickly corrected, commitment 
and sincerity can be directly assessed' (Urry, 2007: 236). Various forms of expression and communication techniques can come into play: indexical expressions, facial gestures, body language, status, voice intonation, pregnant silence, past histories, anticipated conservation and actions and turn-taking practices (ibid.). Boden and Molotch describe how workrelated meetings often begin,

with 'small talk' which contains and projects important substantive matters. Participants update one another on both work and leisure, taking each other's measure in a way that will inform the meetings of later utterances. Premeeting talk typically weaves talk-a-work (personal) with talk-as-work (organizational) in ways that provide formative updates on colleagues' activities and moods, and the phases of talk are skillfully managed as practical matters. ... Such preliminary talk can for example, indicate where the actors have been (e.g. just had a nice slow six-mile run), what they have just done ('closed a deal'), or where they are about to go (I'm leaving for London in an hour). (Boden \& Molotch, 1994: 269-270)

Such face-to-face talk and small talk are important in many academicnetwork activities in order to be able to read and interpret the social context, as described earlier. Thus, according to Urry, people not only feel that they know another human being by having met them personally 'face-to-face' but also that they know a place or a locality by experiencing it themselves, which Urry terms 'face-the-place' (Urry, 2002: 261-262). For academics, this could be the need to visit a field-leading laboratory abroad to work on shared experiments with other researchers and to train and see new methods or techniques which take place there. Another dimension of co-presence is what Urry names 'face-the-moment' which relates to the need to be present at a given live event programmed to run at a specific time (ibid.). From an academic perspective, this dimension particularly relates to seminars, conferences and congresses, which require presence. 


\section{Facing the Conference}

One of the most significant places for academic networking, co-presence and face-to-face interaction, and one which typically generates air travel, is the conference. My previous analysis of work-related travel at Aalborg University shows how more than half of all work-related air travel by the academic staff within a year had conference attendance as its main purpose (Lassen, 2006). A conference is a place to which academics travel to present a paper, publish in conference proceedings, explore what is new in their discipline and keep themselves updated (see e.g. Global Academic Institute, 2020). But a conference is also an arena for a number of other social and less formal activities:

A conference is an arena where international professional contacts may be established, e.g. student exchange cooperation agreements and networks for preparation of joint research projects. ... In those instances where geographic dispersal separates people who need to be in touch, actors turn to conferences. Such meetings serve several purposes: making decisions, seeing how one is heard, executing standard procedures and duties, distributing rewards, status and blame, reinforcing friendship as well as distance, judging commitment, having an enjoyable time and so on. (Høyer \& Næss, 2001: 463)

A conference offers a place for networking for future collaborations and offers the possibility of socialising with colleagues. A conference is about being seen and seeing other people again and about catching up (Wittel, 2001: 67). In this way, a conference is a place of 'organized fortuitousness' (Lassen, 2005: 138). If you attend a seminar, a conference or a congress relevant to your research, you have the opportunity coincidentally to bump into new people, see old acquaintances and friends or get a face for a name you have met only virtually. Such socialising involves a great deal of what Goffman (1967) terms facework. At universities, where employees often know others by name through publications, but not by face or in person, the conference offers an important arena for putting faces to names and making new contacts. If you travel to a network activity to meet new people, then a number of situations will arise to meet by 
chance, for example at a dinner after a conference or for a coffee in the corridor. Attendees may suddenly discover common interests with the person seated next to them, and this may be the start of further cooperation. Academics may not know in advance the relationships they might potentially create by attending, for example, a conference, but they know that the specific event will be a good platform for creating new relationships and maintaining old ones. As a female researcher explains:

It means a lot to me, but it is rarely not like I can say to myself: 'Now I travel to form networks with person a, b and c'. Of course, it sometimes happens that you travel to meet with some very specific people with whom you want to establish some kind of collaboration. However, it is just as much the contacts that arise through such a journey. It is often I come across persons which I later can draw on in different contexts, formally or informally. In the same way, there are sometimes people who turn to me because I have talked to them somewhere. (Lassen, 2005: 141)

In this way, work-related aeromobilities become important instruments for going to such places of organised fortuitousness. Together with various virtual technologies, aeromobility works as a critical element to enable the formation and maintenance of work-related networks and relationships at a distance. In the following section, I will therefore take a closer look at what characterises academics' aeromobility in relation to their work.

\section{Aeromobility: Freedom to Travel?}

I have explored a number of external and internal demands for being mobile that socially and materially are attached to academics' aeromobility, which generally relates to a transformed labour market and specifically relates to the changes that academic work has undergone. However, there is an additional element that is also relevant to highlight, namely the significantly high level of self-determination associated with the aeromobility of academics. This can be seen by comparing a number of the surveys I have conducted over the years of air travellers, primarily at 
global companies and organisations (Lassen, 2005, 2006, 2020). Figure 11.2 shows an average self-determination score calculated on the basis of the question: To what extent do you determine the frequency of your work-related travel? This question has been used in a number of studies of employees in various types of companies. In total, the figure covers responses from 2,818 employees at global companies located in Denmark and Sweden. The surveys cover organisations with significant international air travel within the university sphere, the retail sector, various hardware manufacturers as well as small and medium-sized global

\section{Self-determination score}

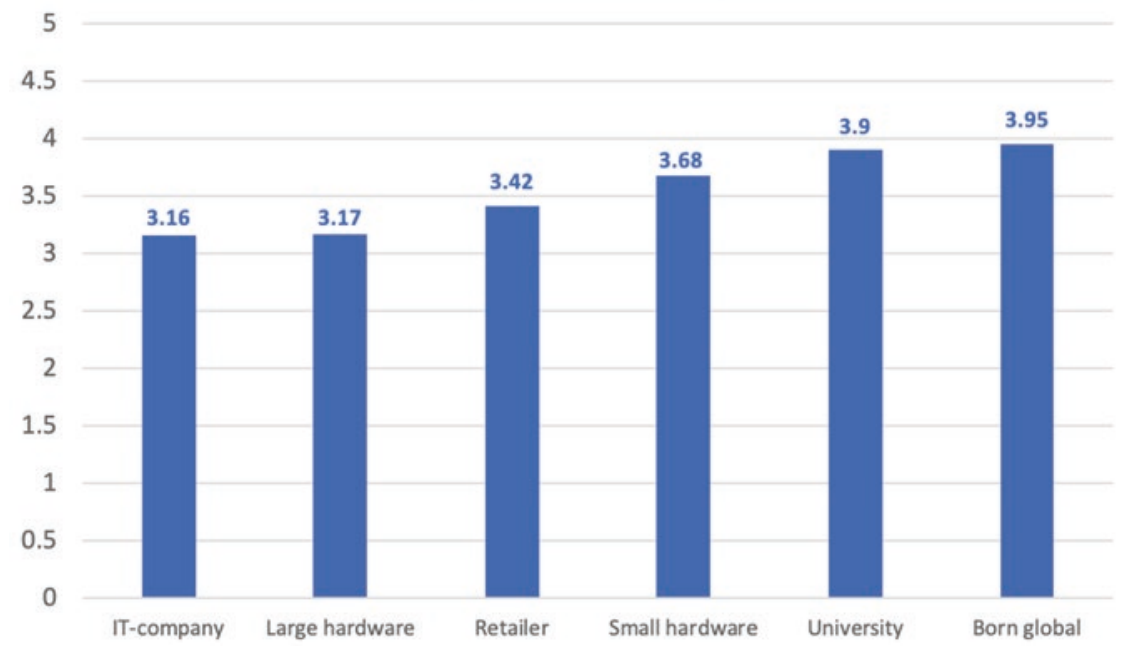

Fig. 11.2 This diagram shows a calculated average self-determination score for each organisation. Total self-determination is allocated 5 points, no selfdetermination 1 point and 4,3 and 2 points are distributed in a similar fashion. These are allocated for responses to the question: 'To what extent do you determine the frequency of your work-related travel?' (on a fluid scale from 1 to 5). The figure is based on two different data sets, collected in 2003 (IT-company $N=$ 144, University $N=379$ ) and 2020 (Large hardware $N=1565$; Retailer $N=233$; Small hardware $N=437$; Born global $N=60$ ), respectively, at a number of Danish and Swedish global companies (see Lassen, 2005, 2006, 2020 for more details). The category 'born global' covers surveyed employees at a number of small and medium-sized companies in Denmark. All of the names of the companies are anonymised in the figure because some of the companies have requested anonymity 
companies. Figure 11.2 draws on different sets of data collected at different times and in different contexts (with all the associated reservations to which this gives rise).

However, it shows that the university as a workplace has the secondhighest degree of self-determination, surpassed only by small and medium-sized global companies. These typically have fewer than 20 employees and are often managed by the owner with a significantly high degree of self-determination in relation to travel and where the owner typically carries out a significant part of the total yearly air travel. The figure illustrates how the self-management and self-determination elements of academic work also clearly stand out in relation to aeromobility. University employees have a considerably stronger influence on their aeromobility praxis than the other forms of companies included. The fact that decision-making in relation to aeromobility is, to a large extent, in the hands of the individual academic, other components and rationalities than work influence how the individual academic interprets such obligations. These other factors are related not only to work but to the very different spheres of everyday life, family, consumption, tourism, leisure and play. Put differently, the level of aeromobility is not something given or fixed, as it is constructed differently by each employee taking account of structural demands and more individual wishes, needs and dreams (Lassen, 2010: 190).

\section{Do Meetings Have a Future?}

As mentioned earlier, virtual mobility plays an important role in networkbased academic work. Virtual mobilities include emails, phone calls, voice messages, video conferencing, virtual meetings, webinars and social media. Such virtual communication technologies are used to be in contact with the workplace, networks, friends and family, and in this way, it acts as a substitute for that you cannot be physically present and manage your obligations (see Lassen, 2005: 165). In this way, virtual communication provides an important tool for maintaining work-on-the-move by both travelling and simultaneously being present online. Virtual communication thus sets the frame for a strange combination of proximity 
and distance, near and far, and for what is and is not virtual (Urry, 2002: 269). The relationship between physical travel and virtual communication has been eagerly discussed among researchers in recent decades. Denstadli and Gripsrud highlight how at least four possible impacts of virtual communication on travel can be identified across various studies: (1) substitution (telecommunications eliminate trips that would have been taken if the technology did not exist); (2) complementarity (telecommunications have a generating effect on travel); (3) modification (telecommunications may change time, mode and destination of a trip) and (4) neutrality (telecommunications and travel operate as independent systems) (Denstadli \& Gripsrud, 2010: 225).

In relation to travel by academics, Storme et al. (2017) show how virtual mobility does not provide a substitute for physical movement. So far, it has not been the solution to the demand for academic mobility. Instead, they argue that "virtual mobility allows "the best of both worlds" through a rational combination of corporeal and virtual mobility when conflicts arise, and obligations of presence at multiple locations exist' (Storme et al., 2017: 420). This means, as the authors conclude, that virtual mobility mostly works as a means of sustaining networks over time, given the processual nature of 'meetingness' rather than reducing the level of physical mobility carried out by academics. As Urry also points out, virtual mobilities (and communication technologies) cannot in a simple way be assumed to substitute the need for co-presence (Urry, 2002, 2003). Furthermore, Urry argues that we must both understand how new forms of transport and communication are converging and that these over time, transform the needs and characteristics of co-presence (Urry, 2002: 269). It is thus a mix of different virtual and physical mobilities that create the framework for physical human proximity and copresence (Ibid.: 268). However, Urry points out that it is still the case that periodic co-presence remains a critical component within the framework of the various virtual mobilities and networks (Ibid.: 269).

The question that arises, however, is how COVID-19 crises potentially will influence the way academics in the future assess the need to be physically present face-to-face, and to use air travel. By the assessment of some organisers of various events, meetings and conferences organisers assessment, COVID-19 has changed live events, not only as a response to the 
present pandemic but also more importantly for the longer term (Intouch Solutions, 2020). Others talk about a future with blended online and face-to-face meetings:

Online meetings have long been seen as a poor substitute for face-to-face ones. With the COVID-19 pandemic and the responses from governments around the world, this view has changed. Online meetings are now a necessity for many organisations. The question is no longer 'should we use online meetings despite their drawbacks?' but rather 'how can we use online meetings effectively?' and 'how do we blend online with face-to-face meetings?' (DiploFoundation, 2020)

In line with this, other organisers stress that post-COVID-19, business travel and meetings will look very different and we will see hybrid eventsa live event plus the option to participate virtually (Convene, 2020). In relation to this, I would argue that the COVID-19 pandemic has increased the awareness of the fact that the need to meet face-to-face is not always the same in all work situations (see above). In the sections that follow, I will therefore present a reflexive tool that provides a more detailed understanding of the types of meetings that in some situations particularly require co-presence and face-to-face communication, and those that can just as well-or perhaps even better and more efficiently - be carried out as virtual meetings. Based on my previous work (Lassen, 2005, 2006), I will show how different meeting needs and formats can be identified in relation to the need for co-presence. I illustrate this through four typical situations (see Fig. 11.3), which attempt to summarise a number of examples in which academic workers are more likely to choose one particular form of communication (virtual or face-to-face) versus more 'open' situations. In two of the four situations, a particular form of communication is most

\begin{tabular}{c|l|l|}
$\begin{array}{c}\text { Relation to participants/ } \\
\text { The nature of the meeting }\end{array}$ & \multicolumn{1}{|c|}{ High acquaintance } & Low acquaintance \\
\hline Formal & Situation 1: Virtual meeting & $\begin{array}{l}\text { Situation 3: Virtual meeting (or face- } \\
\text { to-face meeting) }\end{array}$ \\
\cline { 2 - 3 } Informal & $\begin{array}{l}\text { Situation 2: Face-to-face (or virtual } \\
\text { meeting) }\end{array}$ & Situation 4: Face-to-face meeting \\
\cline { 2 - 3 }
\end{tabular}

Fig. 11.3 Different meeting needs and formats. Based on Lassen (2005: 234) 
often preferred (Situations 1 and 4), while in the remaining two (Situations 2 and 3 ) it is more open and contextual (see Fig. 11.3).

The first situation is where the employees know each other and where the purpose of the meeting is formal (Situation 1). For example, an international research project often holds routine meetings with a formal agenda around project management issues. The second situation is where employees have an informal agenda and know each other in advance (Situation 2). Here the result can be both a physical journey and a virtual meeting. Some situations, for example having to agree on new collaborations or joint publications, require face-to-face socialisation at a conference or seminar. In other situations it will be possible to meet virtually, for example, researchers who know each other well and who meet through a virtual meeting on the screen to work on a new paper may also use the opportunity to socialise, to update and to catch up, and perhaps enter into new agreements. The third situation is where employees do not know each other in advance and have a formal agenda (Situation 3). For example, in a newly started transnational research group that has only existed for a short period and where the participants have little knowledge of each other. Here, the group will probably need to meet physically face-toface to get to know each other better, but in other situations where there may only be a short-term collaboration, this may not be necessary to do the job. The fourth situation is where the form of social interaction is informal, and the participants do not know each other in advance (Situation 4). This would include, for example, a situation where an academic needs to attend a conference to create new network relations. The employee does not know anyone in advance, and the agenda is informal, as it is a matter of socialising with potential network connections. Here, employees will potentially choose to travel to be physically co-present and be able to meet others face-to-face. It is important to stress that there are, of course, many other examples than those mentioned. The examples serve primarily to illustrate how the need for physical co-presence will vary greatly depending on the nature and content of the meeting (Lassen, 2005: 233-234). 


\section{Aeromobility Management: A Way to Work with Air Travel and Meeting Demands at Universities}

However, if greater awareness of a more reflective approach towards the use of physical meetings should be achieved more permanently in academic work, a number of conditions must be in place for this to be implemented. A number of conditions have changed since I originally developed the above model. In 2005, there was a much lower recognition of the climate issue in relation to aviation at both the societal and the individual level (see also Lassen 2009 on the gap between environmental consciousness and air travel praxis). Therefore, at that time, it was very much a matter of first creating an understanding of the problem before the tool itself could come to work. Today, the situation is different as there is much greater recognition of the problem at the societal, individual and company levels than before. My hypothesis (which needs to be investigated further in future studies) is, however, that although many universities and other forms of knowledge institutions carry out research on climate change, environment, transport, travel, communication technologies, organisational theory and so on, they are often behind private companies and other areas of the public sector when it comes to actively work with travel management within their own organisation. Traditional travel management can be defined as a discipline that focuses on corporate travel in relation to providing a strategy for the organisation to be able to tackle and optimise the travel needs of the employees. The argument is here that the above-presented meeting tool needs to be part of a larger focus on aeromobility management (Lassen, 2005) at universities if the tool is to make a difference. Compared to a more conventional regulatory approach, such a concept aims at the genesis of air travel in terms of understanding how the need for a journey is created at an early stage in the decision-making process and seeks change through such an understanding. In that respect, the concept also theoretically draws on the general ideas from the field of mobility management.

The aeromobility management concept is thus about working at an organisational level to create a stronger reflective link between individual 
consciousness and their praxis. This seems particularly relevant in a workplace such as a university where, as shown earlier, there is a high degree of self-determination in relation to work travel. Specifically, the aeromobility management concept consists of five phases (ibid.: 358-360). In the first phase, a division and key persons are identified who are appointed by management as responsible for further aeromobility management in the organisation. This can typically be HR or finance. In the second phase, a mobility analysis of the organisation, which involves both qualitative and quantitative methods, is carried out with the aim of exploring and mapping out the air travel patterns in relation to the different work areas, tasks and needs. In the third phase, with a point of departure in the mobility analysis, a dialogue is created with the employees on future goals of international work-related travel in the organisation and the specific content of a mobility plan for the organisation. In the fourth phase, a concrete mobility strategy and a mobility plan are formed on the basis of the output of the first three phases. Such a mobility plan includes air travel policy and guidelines, a meeting management strategy, virtual technological needs, allocation of necessary resources, establishment of management systems that support the plan, a strategy for internal and external communication of the plan and so on. In the fifth phase, this mobility plan is finally implemented in the organisation and put in motion (see Lassen, 2005 and Lassen, 2009b for further detail on this concept). The presented meeting tool in Fig. 11.3 is especially relevant in phases 3 and 5 . The point of initiating the strategical work on aeromobility management at the university is that it will raise awareness of the individual travel needs and support that the academic employees and the organisation continuously consider their air travel and meeting practices.

\section{Conclusion and Perspectives}

This chapter has focused on how increasing academic air travel in recent decades is part of the larger transformation and globalisation of modern work life. This has seen a shift from industrial and hierarchical work towards much more flexible, networked and mobile work where air travel is often a critical component. However, the climate crisis has put such 
work practices under pressure. I examined the importance of aeromobilities for late modern work, which establishes the context for contemporary academic work practices and, in particular, for transformed academic work. Moreover, the chapter shows how physical meetings and face-toface interaction play an important role in academic work and aeromobilities. Physical co-presence creates relationships, acquaintances and friendships. New and existing network relations are important for career opportunities because they provide access to knowledge, partners, projects and resources. This chapter has shown that, on the one hand, a globalised academic labour market creates a high expectation for individual academics to be aeromobile on a global scale. On the other hand, there exists a significant individual decision-making power in relation to air travel, which for academics is also higher than for air travellers from other global sectors and industries. I have argued that if an aeromobilised academic work practice in the future should be carried out with a lower climate footprint, a stronger differentiation between the forms of meetings and co-presence obligations is necessary. Academics and academic institutions generally need to provide a more detailed understanding of which types of meetings particularly require co-presence and face-to-face communication, and which types of meetings could just as well-or perhaps even better and more efficiently-be carried out as virtual meetings.

In order to instil such a new practice, a tool is presented to assess the need to be physically co-present in different work and meeting situations. I therefore end this chapter by arguing that a movement towards a more differentiated meeting approach among academic and academic institutions seems to require a much greater focus on 'aeromobility management' at academic institutions in the future. The idea of such a concept is to work more strategically with travel goals, strategies and policies to cope with travel and meetings at an organisational level based on green sustainability goals. In other forms of knowledge companies, there has historically been a much stronger tradition to work strategically with travel management. Inspiration from this field seems to hold a potential for more reflexive practice in academia in relation to the management of future air travel and meetings. 


\section{References}

Adey, P. (2010). Mobility. Routledge.

Bauman, Z. (1998). Globalization: The human consequences. Columbia University Press.

Bauman, Z. (1993). Postmodern ethics. Blackwell.

Boden, D., \& Molotch, H. L. (1994). The compulsion of proximity. In R. Friedland \& D. Boden (Eds.), NowHere: Space, time and modernity (pp. 257-286). University of California Press.

Beck, U. (2002). The cosmopolitan perspective: Sociology in the second age of modernity. British Journal of Sociology, 51, 79-105.

Castells, M. (1996). The information age: Economy, society and culture, vol. 1: The rise of the network society. Blackwell.

Castells, M. (2001). The internet galaxy. Reflections on the internet, business, and society. Oxford University Press.

Convene. (2020). The New World of Events After COVID-19: What Returns and What Changes. Retrieved November 15, 2020, from https://convene. com/catalyst/events-after-coronavirus/.

Cwerner, S., Kesselring, S., \& Urry, J. (Eds.). (2009). Aeromobilities. Routledge.

Denstadli, J. M., \& Gripsrud, M. (2010). Face-to-face by travel or picture-The relationship between travelling and video communication in business settings. In J. V. Beaverstock, B. Derudder, J. Faulconbridge, \& F. Witlox (Eds.), International business travel in the global economy (pp. 217-238). Ashgate.

DiploFoundation. (2020). COVID-19: A time to adapt. Retrieved November 15, 2020, from www.diplomacy.edu/covid-19.

Elliott, A., \& Urry, J. (2010). Mobile lives. Routledge.

Feld, S., \& Charter, C. (1998). Foci of activity as changing contexts of friendship. In R. G. Adams \& G. Allan (Eds.), Placing friendship in context (pp. 136-152). Cambridge University Press.

Fumasoli, T., Goastellec, G., \& Kehm, B. M. (2017). Academic careers and work in Europe: Trends, challenges, perspectives. In T. Fumasoli, G. Goastellec, \& B. M. Kehm (Eds.), Academic work and careers in Europe: Trends, challenges, perspectives (pp. 201-214). Springer.

Global Academic Institute. (2020). Reasons to attend international academic conferences. Retrieved November 15, 2020, from https://www.globalacademicinstitute.com/8-reasons-to-attend-international-academic-conferences/.

Goffman, E. (1967). Interaction ritual: Essays on Face-to-Face Behavior. Pantheon Books. 
Gössling, S., \& Humpe, A. (2020). The global scale, distribution and growth of aviation: Implications for climate change. Global Environmental Change, 65, 102194. https://doi.org/10.1016/j.gloenvcha.2020.102194

Henkel, M. (2005). Academic identity and autonomy in a changing policy environment. Higher Education, 49(1), 155-176. https://doi.org/10.1007/ s10734-004-2919-1

Høyer, K. G., \& Næss, P. (2001). Conference tourism: A problem for the environment, as well as for research? Journal of Sustainable Tourism, 9, 451-470. https://doi.org/10.1080/09669580108667414

Intouch Solutions. (2020). Executive Summary. Retrieved November 15, 2020, from https://www.intouchsol.com/blog/impact-of-covid-19-on-medicalconferences-and-live-events/.

Jensen, O. B. (2013). Staging Mobilities. Routledge.

Jones, A. (2008). The rise of global work. Transactions, 33, 12-26. https://doi. org/10.1111/j.1475-5661.2007.00284.x

Kaufmann, V. (2002). Re-thinking mobility: Contemporary sociology. Ashgate.

Kaufmann, V., \& Audikana, A. (2020). Mobility capital and motility. In O. B. Jensen, C. Lassen, V. Kaufmann, M. Freudendal-Pedersen, \& I. S. G. Lange (Eds.), 2020 Handbook of urban mobilities (pp. 41-47). Routledge.

Kellerman, A. (2010). Business travel and leisure tourism: Comparative trends in a globalizing world. In J. V. Beaverstock, B. Derudder, J. Faulconbridge, \& F. Witlox (Eds.), International business travel in the global economy (pp. 165-176). Ashgate.

Kirn, W. (2001). Up in the air. Anchor Books.

Lassen, C. (2005). Den mobiliserede vidensmedarbejder: En analyse af internationale arbejdsrejsers sociologi. Ph.D. thesis, Department for Planning and Society. Aalborg: Aalborg University.

Lassen, C. (2006). Aeromobility and Work. Environment and Planning A, 38(2), 301-312. https://doi.org/10.1068/a37278

Lassen, C. (2009a). A life in corridors: Social perspectives on aeromobility and work in knowledge organisations. In S. Cwerner, S. Kesselring, \& J. Urry (Eds.), Aeromobilities (pp. 177-193). Routledge.

Lassen, C. (2009b). Networking, knowledge organizations and aeromobility. Geografiska Annaler: Series B, Human Geography, 91(3), 229-243. https://doi. org/10.1111/j.1468-0467.2009.00317.x 
Lassen, C. (2010). Individual rationalities of global business travel. In J. V. Beaverstock, B. Derudder, J. Faulconbridge, \& F. Witlox (Eds.), International business travel in the global economy (pp. 177-194). Ashgate.

Lassen, C. (2020). Patterns of work-related air travel in global companies. Unpublished research note. Aalborg Universitet.

Lassen, C., \& Jensen, O. B. (2004). Den Globale Bus: om arbejdsrejsers betydning i hverdagslivet. In M. H. Jacobsen \& J. Tonboe (Eds.), Arbejdssamfundet: Den beslaglagte tid og den splittede identitet (pp. 241-279). Hans Reitzels Forlag. Sennett, R. (1998). The corrosion of character. The personal consequences of work in the new capitalism. W.W. Norton \& Company.

Statista. (2020). Number of scheduled passengers boarded by the global airline industry from 2004 to 2021. Retrieved November 15, 2020, from https:// www.statista.com/statistics/564717/airline-industry-passengertraffic-globally/.

Storme, T., Faulconbridge, J. R., Beaverstock, J. V., Derudder, B., \& Witlox, F. (2017). Mobility and professional networks in academia: An exploration of the obligations of presence. Mobilities, 12(3), 405-424. https://doi.org/1 $0.1080 / 17450101.2015 .1116884$

Urry, J. (2002). Mobility and proximity. Sociology, 36, 255-274. https://doi. org/10.1177/0038038502036002002

Urry, J. (2003). Social networks, travel and talk. British Journal of Sociology, 54(2), 155-175. https://doi.org/10.1080/0007131032000080186

Urry, J. (2007). Mobilities. Routledge.

Vesala, H. V., \& Tuomivaara, S. T. (2020). Mobile work, space and processes of transition. In O. B. Jensen, C. Lassen, \& I. S. G. Lange (Eds.), Material mobilities (pp. 223-239). Routledge.

Wellman, B., \& Haythornthwaite, C. (Eds.). (2002). The internet in everyday life. Blackwell.

Wittel, A. (2001). Toward a network sociality. Theory, Culture and Society, 18(6), 51-75. https://doi.org/10.1177/026327601018006003 
Open Access This chapter is licensed under the terms of the Creative Commons Attribution 4.0 International License (http://creativecommons.org/licenses/ by/4.0/), which permits use, sharing, adaptation, distribution and reproduction in any medium or format, as long as you give appropriate credit to the original author(s) and the source, provide a link to the Creative Commons licence and indicate if changes were made.

The images or other third party material in this chapter are included in the chapter's Creative Commons licence, unless indicated otherwise in a credit line to the material. If material is not included in the chapter's Creative Commons licence and your intended use is not permitted by statutory regulation or exceeds the permitted use, you will need to obtain permission directly from the copyright holder.

(c) (i) 